\title{
Enhanced Retinal Ganglion Cell Survival in Glaucoma by Hypoxic Postconditioning After Disease Onset
}

\author{
Jeffrey M. Gidday • Lihong Zhang • Chia-Wen Chiang • \\ Yanli Zhu
}

Published online: 31 December 2014

(C) The American Society for Experimental NeuroTherapeutics, Inc. 2014

\begin{abstract}
The neuroprotective efficacy of adaptive epigenetics, wherein beneficial gene expression changes are induced by nonharmful "conditioning" stimuli, is now well established in several acute, preclinical central nervous system injury models. Recently, in a mouse model of glaucoma, we demonstrated retinal ganglion cell (RGC) protection by repetitively "preconditioning" with hypoxia prior to disease onset, indicating an epigenetic approach may also yield benefits in chronic neurodegenerative disease. Herein, we determined whether presenting the repetitive hypoxic stimulus after disease initiation [repetitive hypoxic "postconditioning" (RHPost)] could afford similar functional and morphologic protection against glaucomatous RGC injury. Chronic elevations in intraocular pressure (IOP) were induced unilaterally in adult male C57BL/6 mice by episcleral vein ligation. Mice were randomized to an RH-Post [1 h of systemic hypoxia (11\% oxygen) every other day, starting 4 days after IOP elevation] or an untreated control group. After 3 weeks of experimental glaucoma, the $21-27 \%$ reduction and 5-25\% prolongation in flash visual-evoked potential amplitudes and latencies, respectively, and the $30 \%$ impairment in visual acuity were robustly improved in RH-Post-treated mice, as was the $17 \%$ loss in
\end{abstract}

J. M. Gidday $(\bowtie) \cdot$ L. Zhang $\cdot$ Y. Zhu

Department of Neurosurgery, Washington University School of

Medicine, St. Louis, MO 63110, USA

e-mail: gidday@wustl.edu

\section{J. M. Gidday}

Department of Ophthalmology \& Visual Sciences, Washington

University School of Medicine, St. Louis, MO 63110, USA

\section{J. M. Gidday}

Department of Cell Biology \& Physiology, Washington University

School of Medicine, St. Louis, MO 63110, USA

\section{C.-W. Chiang}

Department of Radiology, Washington University School of

Medicine, St. Louis, MO 63110, USA
RGC soma number and $20 \%$ reduction in axon integrity. These protective effects were observed without RH-Post affecting IOP. The present findings demonstrate that functional and morphologic protection of RGCs can be realized by stimulating epigenetic responses during the early stages of disease, and thus constitute a new conceptual approach to glaucoma therapeutics.

Key Words Glaucoma · neuroprotection · epigenetics · retina $\cdot$ optic nerve

\section{Introduction}

Glaucoma includes a family of optic neuropathies that collectively represent the second leading cause of blindness in the world [1]. Neuroprotection-based therapies for protecting retinal ganglion cells (RGCs) from the damage induced by progressive and sustained increases in intraocular pressure (IOP) have yet to be successful in the limited number of clinical trials to date, leaving surgery or IOP-lowering drugs as the clinical mainstays for treating patients with this disease. Because RGC injury pathways in glaucoma are multifactorial and involve both soma- and axon-dependent mechanisms, it is unlikely that a monotherapy-based treatment strategy will ever prove viable.

Accumulating evidence indicates that a mechanistically pleiotropic approach to neuroprotection in acute central nervous system (CNS) injury can be afforded by an adaptive epigenetics-based therapy, wherein beneficial changes in gene expression are induced by a mild "conditioning" stressor [2-4]. In the setting of retina ischemia, we, and others, have shown that a brief, noninjurious hypoxic or ischemic 
preconditioning stimulus provides a short window of protection for RGCs and other retinal cells [5-7]. That the duration of this "therapeutic window" could be extended from days to weeks by repeatedly exposing mice to systemic hypoxia prior to ischemia [8] led us to hypothesize that this treatment approach might also be protective against the slow loss of RGCs that characterizes glaucoma. Indeed, we recently documented robustly enhanced survival of RGC soma and axons in an inducible mouse model of open-angle glaucoma by repetitive hypoxic preconditioning ( $\mathrm{RH}-\mathrm{Pre}$ ) [9].

Translationally speaking, the ability to activate such an innate protective response in patients already presenting with the early stages of glaucoma, and to significantly reduce the progression of RGC injury (and consequent vision loss), would represent a unique, clinically attractive therapeutic strategy for this disease. Thus, the present study was undertaken to determine whether "postconditioning" with repetitive hypoxia (RH-Post), initiated after IOP elevation, could still afford significant RGC protection in experimental glaucoma.

\section{Methods}

\section{Animals}

All experimental methods and animal care procedures employed were approved by the Animal Studies Committee at Washington University, and performed in accordance with National Institutes of Health and Association for Research in Vision and Opthalmology guidelines for the care and use of laboratory animals.

Mice were randomized into either an untreated glaucoma group or a glaucoma group with RH-Post. This involved a total of 7, 1-h exposures of the animals to systemic hypoxia (11\% oxygen) over the 3 weeks following IOP elevation; the initial RH-Post stimulus of the 7 exposures was administered starting 4 days after episcleral vein ligation (Fig. 1).

\section{Experimental Glaucoma Model}

As we described previously [9-11], a sustained, 3-week period of elevated IOP was achieved by repeated ligation of the episcleral veins of one eye; the fellow eye of each mouse served as a nonglaucomatous control. In brief, after ketamine/xylazine-anesthetized mice received topical application of $0.5 \%$ proparacaine hydrochloride, the conjunctiva and Tenon's capsule were incised to expose the episcleral veins, 3-4 of which over $>300^{\circ}$ of the limbus were severed secondary to doubly ligating them with 11-0 nylon suture (Alcon Surgical, Fort Worth, TX, USA). Throughout the surgical procedure, core body temperature was maintained at $37^{\circ} \mathrm{C}$ using a thermoregulated heating pad. Mice were administered topical antibiotic and then allowed to recover in their home cages. Additional ligations of $\geq 1$ presumably patent episcleral veins were performed at $24 \mathrm{~h}$, and at 1 or 2 weeks following the initial surgery, if IOP was not elevated at $24 \mathrm{~h}$ or did not remain elevated at weekly measurement intervals, or if newly formed episcleral veins became evident. Of note, in this study and in our previous studies employing this same model [9-11], very few mice required additional ligation surgery at $24 \mathrm{~h}$ or 2 weeks after the initial ligation; rather, in most mice, new veins that became apparent by 1 week were ligated, even if IOP had not fallen below levels measured at $24 \mathrm{~h}$. As described previously by us and others [9-12], IOP determinations were made between 10.00 am and $2.00 \mathrm{pm}$ in both eyes prior to, and at weekly intervals following, IOP elevation using the TonoLab Rebound Tonometer system (Colonial Medical Supply, Franconia, NH, USA).

Elevated IOP was also induced in several other cohorts of animals to examine the possibility that inner retinal ischemia may result from our episcleral vein ligation procedure. Distinct ischemic injury phenotypes were assessed in central and peripheral retinal cross-sections obtained $24 \mathrm{~h}, 1$ week, and 3 weeks after IOP elevation, including determinations of retinal cell layer and plexiform layer thinning, cleaved caspase- 9 and cleaved caspase- 3 protein expression, and the presence of terminal deoxynucleotidyl transferase deoxyuridine triphsophate nick end labeling (TUNEL)-positive cells.

\section{Structural Analyses of Potential Ischemic Injury}

Five-micron-thick cross-sections were obtained from paraffin-embedded retinas of mice in which IOP was elevated continuously for either $24 \mathrm{~h}, 1$ week, or 3 weeks. Adjacent sections were stained by hematoxylin and eosin, prepared for TUNEL staining by a commercially available kit (ApopTag Fluorescein In situ Apoptosis Detection Kit, EMD Millipore, Billerica, MA, USA) according to manufacturer's directions, or immunostained for cleaved caspase-3 and cleaved caspase- 9 expression levels. For the latter, the primary antibodies used were from Cell Signaling [Danvers, MA, USA; \#9664 and \#9509 (for cleaved caspase-3 and cleaved caspase-9, respectively), both 1:100 for $2 \mathrm{~h}$ at room temperature], with AlexaFluor 488 (A-21206; lot \#913921, 1:400 for $1 \mathrm{~h}$ at room temperature; Invitrogen, Carlsbad, CA, USA) as the secondary antibody. We searched for caspase 3/9-immunopositive and TUNEL-positive cells across the entire (central and peripheral) retinae. 
Glaucoma Only
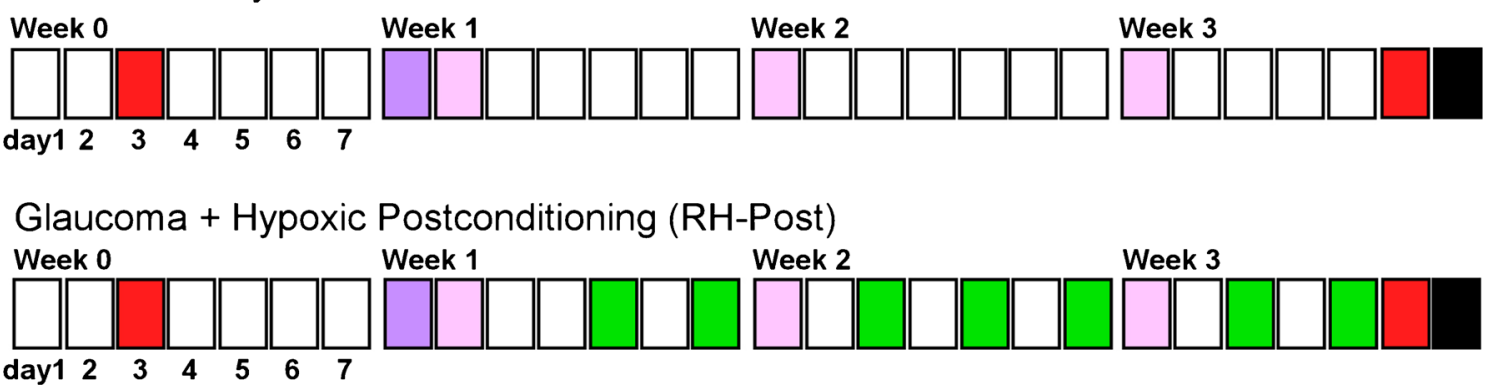

Fig. 1 Experimental protocol. Schematic timeline defining the experimental protocol employed in both study groups. The initial episcleral vein ligation surgery (dark purple) was performed on day 1 of week 1; the 24-h, 1-week, and 2-week follow-up surgeries (light purple) are shown. Flash visual-evoked potential and optometry functional metrics (red) were performed 4 days prior to the initial episcleral vein

Functional Analyses of Glaucomatous Injury and RH-Post-mediated Protection

\section{Flash Visual-Evoked Potentials}

We recorded flash visual-evoked potentials (fVEPs), as described previously [13, 14], using a UTAS Visual Electrodiagnostic Testing System with BigShotTM Ganzfeld (LKC Technologies, Gaithersburg, MD, USA). In brief, mice were anesthetized with ketamine/xylazine, the pupil was dilated with $1 \%$ atropine, corneal anesthesia was applied (procaine, $0.5 \%$ ), followed by hydration maintenance with $2.5 \%$ hypromellose ("Gonak," Akorn, Lake Forest, IL, USA). Animals were placed on a thermoregulated heating pad and held in place by a tooth-holder headset; a 0.25 -mm diameter platinum wire (AA45093BY; Fischer Scientific, Waltham, MA, USA) was inserted under the scalp for $1.0 \mathrm{~cm}$ over the mouse visual cortex and connected to a UBA-4200 digital biomedical amplifier using a "Mini SMD Grabber" test clip lead with jack (model 3782; Pomona Electronics, Everett, WA, USA). A reference needle electrode was placed through the pinna of one ear, and a ground electrode inserted under the skin at the base of the tail. Bilateral fVEP responses were recorded with both eyes open, and both eyes covered with hard contact lenses painted with black nail polish; then, unilateral fVEPs were recorded with the experimental eye or the control eye covered. Resting periods of 5 min were instituted before and between each recording, during which the room was darkened; recordings themselves were obtained under very dim room light. Flash parameters consisted of $0.2 \mathrm{lg}$ $\left(\mathrm{cd}-\mathrm{s} / \mathrm{m}^{2}\right)$ white flashes ( $\leq 5 \mathrm{~ms}$ duration) presented on a dark background, delivered via the Ganzfeld sphere; responses to 80 consecutive flashes presented at $1.9 \mathrm{~Hz}$ were averaged for each trial. After testing, animals received topical antibiotic and were allowed to recover in a $37-{ }^{\circ} \mathrm{C}$ warming chamber until ambulatory, then returned to their home cages. Three distinct amplitudes and latencies from the characteristic fVEP ligation surgery, and the day before the last day of the 3-week period of experimental glaucoma (black), when animals were sacrificed for morphological assessments of retinal ganglion cell soma and axon loss. In the repetitive hypoxic postconditioning (RH-Post) group, mice were exposed for $1 \mathrm{~h}$ to systemic hypoxia (11\% oxygen) on the 7 days shown (green) prior to being killed

waveform (see Fig. 6A for representative trace showing 0 $\mathrm{N} 1, \mathrm{P} 1-\mathrm{N} 1$, and N1-P2) were manually quantified for both eyes of each mouse in a blinded fashion.

\section{Visual Acuity by Optokinetics}

Visual acuity (VA) was assessed in conscious mice by optokinetics, using a commercially available apparatus and the associated software (OptoMotry; Cerebral Mechanics, Lethbridge, AB, Canada), as described previously $[15,16]$. Briefly, mice were placed on a platform in a closed chamber with a projection of virtual cylinders of varying spatial frequency at $100 \%$ contrast. The spatial frequency of the rotating columns was recorded when the head movement of the mouse responding to the rotating columns was observed. VA was defined the highest spatial frequency, in cycles/degree (c/d), to which a given mouse responded. Changing the rotational direction of the cylinder (i.e., clockwise for the left eye and counterclockwise for the right eye), provided independent assessments of the VA of each eye. Baseline VA was determined bilaterally within a week before performing the initial episcleral vein ligation procedure to elevate IOP; VA was then measured again after 3 weeks of experimental glaucoma.

Structural Analyses of Glaucomatous Injury and RH-Post-mediated Protection

Axon integrity was quantified in the postlaminar optic nerve by confocal immunofluorescence microscopy of SMI32immunopositive axons, as described previously by us and others [10, 11, 17-19]; SMI32 has been shown to stain the medium and large, alpha-subtype of RGCs [20, 21], which, while not inclusive of all RGCs, are found evenly distributed throughout the retina [20]. In brief, after obtaining fVEP and optokinetic measurements in untreated and RHP-treated mice after 3 weeks of experimental glaucoma, animals were euthanized by transcardial perfusion, the retina was removed and 
flat-mounted (see below), and an optic nerve segment from the postlaminar region $(50-150 \mu \mathrm{m}$ behind the globe) was fixed overnight in $4 \%$ paraformaldehyde, rinsed three times with phosphate buffered saline, transferred to $10 \%$ formalin, and then paraffin-embedded. Four- $\mu \mathrm{m}$-thick sections perpendicular to the long axis of the nerve were collected, deparaffinized, rehydrated, and subjected to antigen retrieval by immersing the tissue for 10-min in boiling "antigen unmasking solution" (H3300; Vector Laboratories, Burlingame, CA, USA). After a 20-min incubation in blocking buffer, sections were incubated overnight at $4{ }^{\circ} \mathrm{C}$ with primary antibodies against the nonphosphorylated neurofilament heavy subunit SMI-32 (1:1000, mouse monoclonal; Covance, Emeryville, CA, USA), followed by incubation at room temperature for $1 \mathrm{~h}$ with secondary antibody [1:400, goat anti-mouse IgG linked to Alexafluor 488, A11001; Molecular Probes (Eugene, OR, USA) for SMI-32]. VectaShield Hardset Mounting Medium with 4',6-diamidino2-pheynylindole (DAPI) (H-1200; Vector Laboratories) was used for counterstaining nuclei. Confocal images [LSM 5 PASCAL; 40× objective (1.25 NA); Carl Zeiss, Jena, Germany] were obtained at excitation wavelengths of 405 , 488 , and $560 \mathrm{~nm}$. Total fluorescence intensities of SMI32positive axons within the nerve border were determined by binarizing the image after background subtraction to identify the total surface area in the nerve covered by SMI32 above threshold, calculating the total fluorescence intensity of the resulting image, and then normalizing to the total area of SMI32-positive signal, as detailed previously $[10,11]$.

RGC soma viability analyses were undertaken using NeuN immunohistochemistry on retinal flat mounts, as described previously by us and others [10,11,22-24]. NeuN is a well established RGC-specific antigen not found in inner nuclear layer cells [25]; thus, antibodies to NeuN are widely used to differentiate RGCs from displaced amacrine cells in the ganglion cell layer, with a false positive rate when quantified in young mice of no more than $5 \%$ [23]. Briefly, harvested retinae were washed 3 times in Tris-buffered saline and Tween 20 (TBST) buffer, and permeabilized for $30 \mathrm{~min}$ with $0.3 \%$ Triton X-100 (T-9284; Sigma, St. Louis, MO, USA) in TBS buffer. After blocking nonspecific binding with $1 \%$ bovine serum albumin (Jackson ImmunoResearch, West Grove, PA, USA), $0.15 \%$ Triton X-100, and $10 \%$ normal goat serum (Jackson ImmunoResearch) in TBST for $30 \mathrm{~min}$ at room temperature, retinae were incubated overnight at $4{ }^{\circ} \mathrm{C}$ with NeuN [1:500, monoclonal anti-NeuN (MAB377); Chemicon/Millipore, Billerica, MA, USA]. Following TBST wash, secondary antibody $[1: 400$, goat antimouse IgG linked to Alexafluor 568 (A11004); Invitrogen] was applied for $1 \mathrm{~h}$ at room temperature. Thereafter, retinae were flat-mounted with $50 \%$ glycerol (G-5516; Sigma) and coverslipped.

Twelve distinct regions of peripheral retina (3 per quadrant) were examined by confocal fluorescence microscopy (LSM 5
PASCAL, 20× objective, $0.5 \mathrm{NA}$, excitation wavelength $=$ $560 \mathrm{~nm}$; Carl Zeiss). A blinded observer initially established fluorescence thresholds for each experimental/fellow eye pair and applied manual corrections of scanned images to remove signal artifacts; thereafter, AnalySIS software (Soft Image System, Münster, Germany) was used to count automatically NeuN-positive RGC soma, defined as all homogeneously stained and round-in-shape NeuN-positive cell bodies. Resultant counts were analyzed by quadrant, as well as across the entire retina.

\section{Statistics}

All results are provided as means \pm SEM. Data in Figs. 6, 7, 8, and 9 were normalized to the respective values measured in the fellow eye of the untreated control group, so that potential effects of RH-Post on the nonglaucomatous fellow eye, if any, would be revealed. Nonparametric signed rank and rank sum tests were used to identify significant differences between measures from paired eyes in the same animal, and from eyes in different animal groups, respectively, using raw data. Quadrant-to-quadrant comparisons of RGC soma numbers within animals (experimental vs fellow eye) and between animals (untreated vs RH-Post-treated) were identified by repeated measures analysis of variance on ranks followed by the Tukey's test. IOP comparisons within and between animals in both experimental groups over the 3-week period of intraocular hypertension were identified by one-way repeated measures analysis of variance. In all instances, $p<0.05$ was accepted as significant.

\section{Results}

IOP

As we found previously in this model [9-11], sustained increases in IOP were achieved secondary to episcleral vein ligation. Figure 2 shows IOP changes measured in both eyes in mice from the control and RH-Post groups. There were no significant differences in baseline IOP $[10.4 \pm 0.5$ and $11.4 \pm$ $0.5 \mathrm{mmHg}$ for the fellow eyes of the control $(n=16)$ and RHPost $(n=11)$ groups, respectively, and $10.4 \pm 0.5$ to $11.7 \pm$ $0.6 \mathrm{mmHg}$ in experimental eyes of the control and RH-Post groups, respectively] between the experimental groups. The increases in IOP measured in the experimental eyes were significantly greater $(p<0.001$ to $p=0.002)$ at each of the 4 time points than the respective baseline IOP value for that eye, and significantly greater (all $p<0.001)$ than the respective IOP in the corresponding fellow eye at the same timepoint. IOPs in the experimental group ranged from $17.6 \pm 1.0$ to $17.6 \pm$ $1.7 \mathrm{mmHg}$ at $24 \mathrm{~h}$, from $21.4 \pm 1.0$ to $24.4 \pm 1.7 \mathrm{mmHg}$ at 


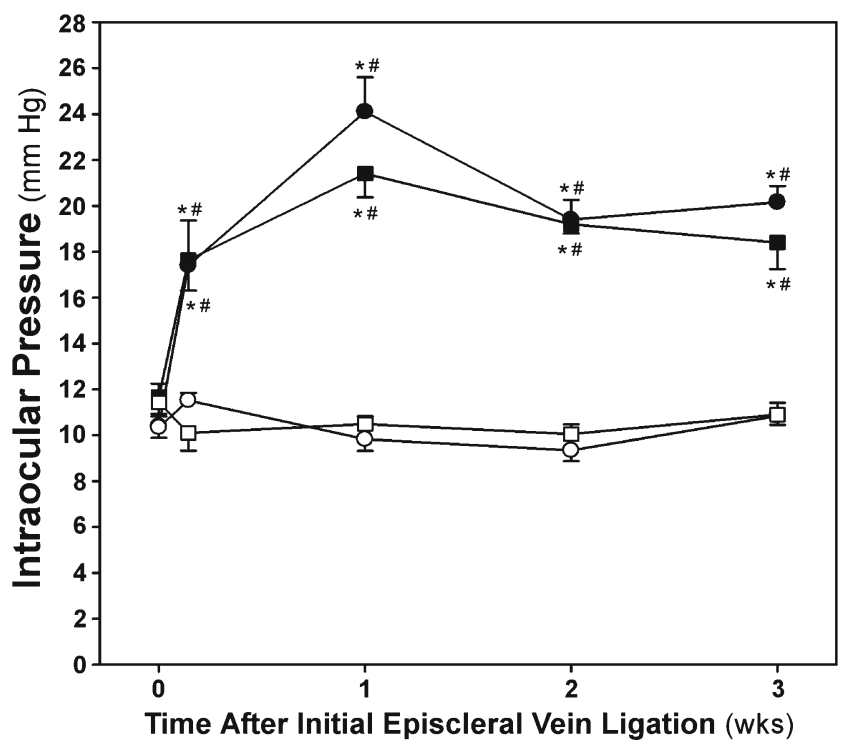

Fig. 2 Intraocular pressure (IOP) in untreated mice and mice with repetitive hypoxic postconditioning ( $\mathrm{RH}-\mathrm{Post}$ ). IOP shown for experimental eyes (filled symbols) and respective fellow eyes (open symbols) in untreated (squares; $n=16$ ) and RH-Post-treated (circles; $n=11$ ) mice. At $24 \mathrm{~h}$, and 1, 2, and 3 weeks, all IOP values for the experimental eyes in each group were significantly different from their respective baselines $(* p<0.05)$ and from their fellow eyes at each time point $\left({ }^{\#} p<0.05\right)$. There was no statistically significant difference in experimental IOP values (mean \pm SEM) between the untreated mice and mice with RH-Post

1 week, from $19.2 \pm 0.4$ to $19.4 \pm 0.9 \mathrm{mmHg}$ at 2 weeks, and from $18.4 \pm 1.2$ to $20.1 \pm 0.8 \mathrm{mmHg}$ at 3 weeks of sustained intraocular hypertension. There were no statistically significant differences in the extent of IOP elevation in the experimental eyes among both groups at any time point. In addition, there were no systematic differences in the number of episcleral vein ligations performed in a given animal and its corresponding IOP, or between the experimental eyes of the untreated and RHPost-treated mice. In sum, the experimental eyes in our study started with the same IOPs and experienced the same elevation in IOP after episcleral vein ligation, independent of whether the mice received the RH-Post treatment or not.
Validation of Lack of Ischemic Injury Secondary to Episcleral Vein Ligation

As shown in the hematoxylin and eosin-stained cross-sections of mid-central retina shown in Fig. 3, there was no evidence of ischemia-induced cell loss in the inner nuclear (and outer nuclear) layers, or thinning of these layers or of the inner or outer plexiform layers, at any time ( $24 \mathrm{~h}, 1$ week, or 3 weeks) after IOP elevation, unlike what we have consistently witnessed previously in this strain 1 week after a $30-45$-min period of complete retinal ischemia induced by elevation of IOP to above systolic blood pressure $[6,8]$.

In addition to hematoxylin and eosin staining, we also performed double immunohistochemical labeling of NeuN-, caspase-3-, and caspase-9-positive ganglion cells in cross-sections of retina from mice in which episcleral vein ligation was performed $24 \mathrm{~h}, 1$ week, and 3 weeks previously [22-24]. As shown in Figs 4 and 5, the retinae look completely normal, with no evidence of cleaved caspase- 9 or cleaved caspase- 3 expression in any cell layer at any time after elevating IOP, other than in the ganglion cell layer at later time points, where and when glaucomatous cell death is to be expected. Specifically, in neither the central nor peripheral retina of glaucomatous eyes did we find cells in the ganglion cell layer that were immunopositive for either enzyme at $24 \mathrm{~h}$, and only for cleaved caspase-3 could we find a very rare, immunopositive cell in the ganglion cell layer of the peripheral retina at 1 week (Fig. 5). After 3 weeks of experimental glaucoma, occasional cleaved caspase-9-positive cells (Fig. 4) and occasional cleaved caspase-3-positive cells (Fig. 5) could be found in the ganglion cell layer of the peripheral retina. These caspase-9- and caspase-3positive cells were always co-localized with NeuNpositive cells, as shown in the individual panels and in the merged photomicrographs in Figs. 4 and 5, supporting their identity as RGCs. Interestingly, the caspase-9- and caspase-3-positive cells did not co-localize with the

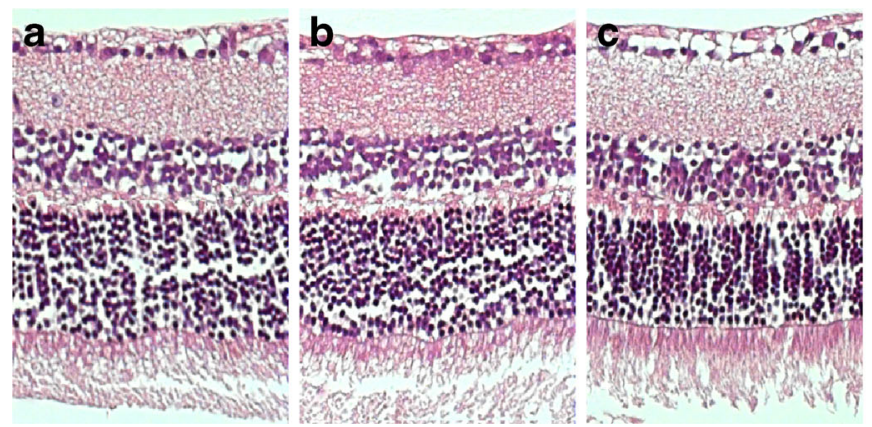

Fig. 3 Lack of ischemic injury following episcleral vein ligation. Hematoxylin and eosin-stained cross-sections of mid-central retinae from $(\mathrm{B}, \mathrm{D}, \mathrm{F})$ glaucomatous and $(\mathrm{A}, \mathrm{C}, \mathrm{E})$ matched fellow eyes obtained (A, B) 24 h, (C, D) 1 week, and (E, F) 3 weeks after

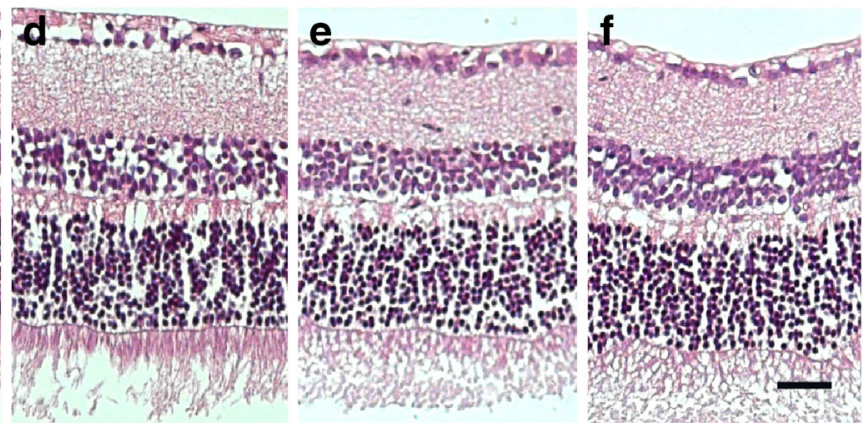

intraocular pressure elevation by episcleral vein ligation. Note, no evidence of ischemic injury in the inner or outer retina is present at any time. Scale bar $=50 \mu \mathrm{m}$ 
Fig. 4 Cleaved caspase-9

immunohistochemistry after

episcleral vein ligation. Cleaved

caspase-9 immunohistochemistry in representative retinae from

experimental glaucoma (GL) eyes and fellow eyes obtained (A) $24 \mathrm{~h}$

(upper), (A) 1 week (lower), and (B) 3 weeks after episcleral vein ligation. Cleaved caspase-9

(green) shown with NeuN (red) for retinal ganglion cell (RGC) identification, 4',6-diamidino-2phenylindole (DAPI; blue) to mark nuclei, and merged images. Note, only after 3 weeks of experimental glaucoma were caspase-9-positive cells apparent across the retina, and only then in a cytoplasmic location in some cells in the ganglion cell layer, identified as RGCs by coimmunostaining with NeuN (arrowheads). Scale bar (shown in Fig. 5) $=30 \mu \mathrm{m}$ a

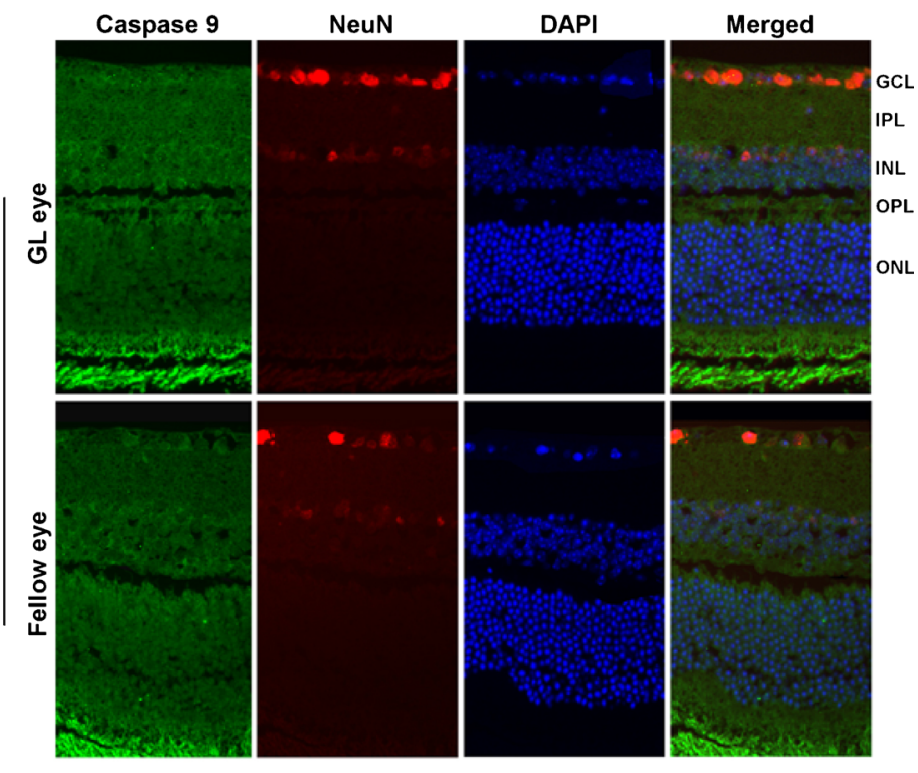

GL/24h

|⿺辶一兀

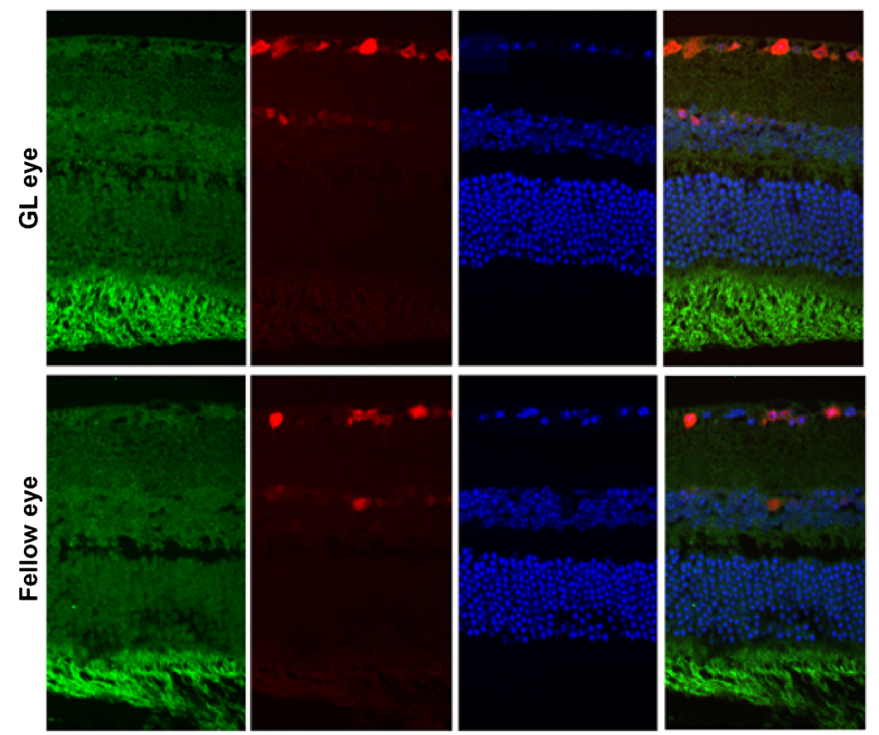

b

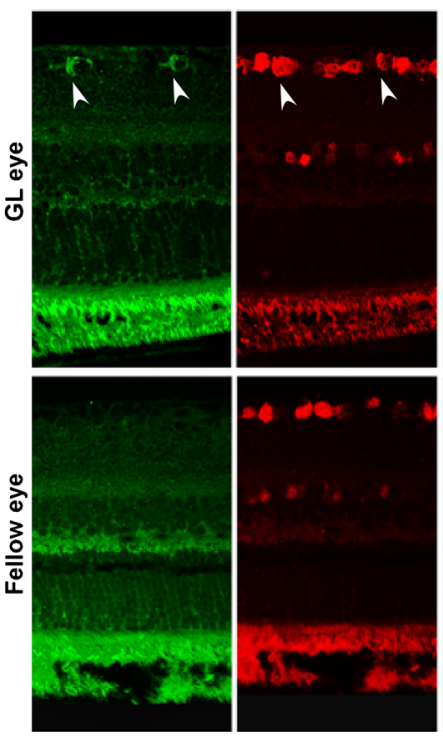

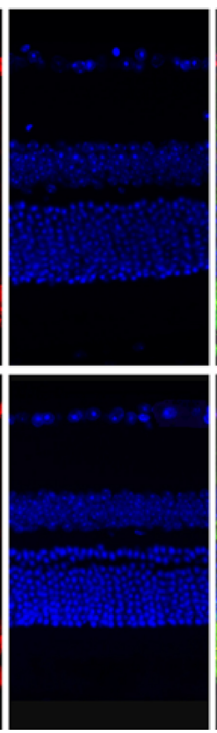

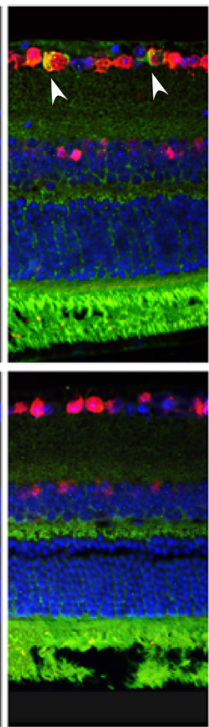


Fig. 5 Cleaved caspase-3

immunohistochemistry after

episcleral vein ligation. Cleaved

caspase-3 immunohistochemistry

in representative retinae from

experimental glaucoma (GL) eyes

and fellow eyes obtained (A) $24 \mathrm{~h}$

(upper), (A) 1 week (lower), and

(B) 3 weeks after episcleral vein

ligation. Cleaved caspase-3

(green) shown with $\mathrm{NeuN}$ (red)

for retinal ganglion cell (RGC)

identification, the nuclear marker

4',6-diamidino-2-phenylindole

(DAPI; blue), and merged

images. Note, caspase-3-positive

cells were not evident at $24 \mathrm{~h}$, but

cytoplasmic staining was seen

occasionally 1 or 3 weeks after

episcleral vein ligation in the

retinal ganglion cell layer, in cells co-immunopositive for the RGC marker NeuN (arrowheads). Scale bar $=30 \mu \mathrm{m}$ a

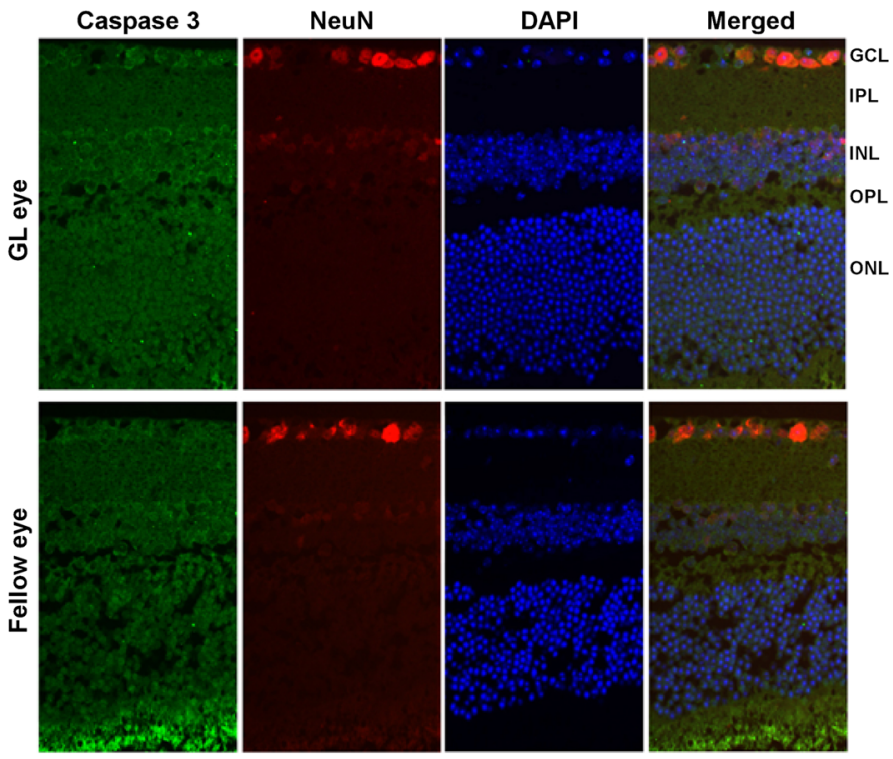

GL/1wk

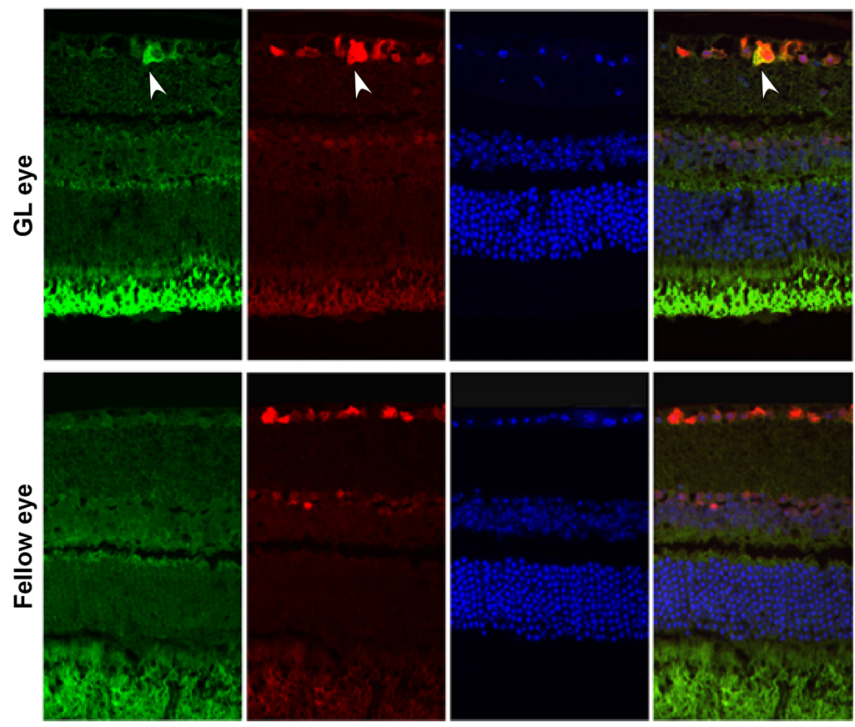

b

GL/3wks

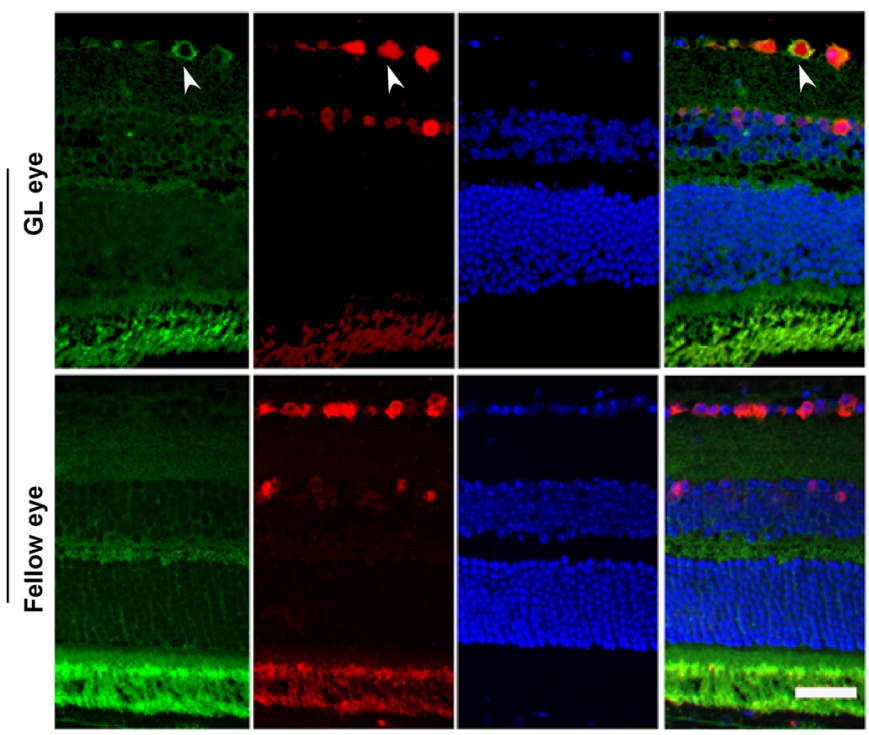




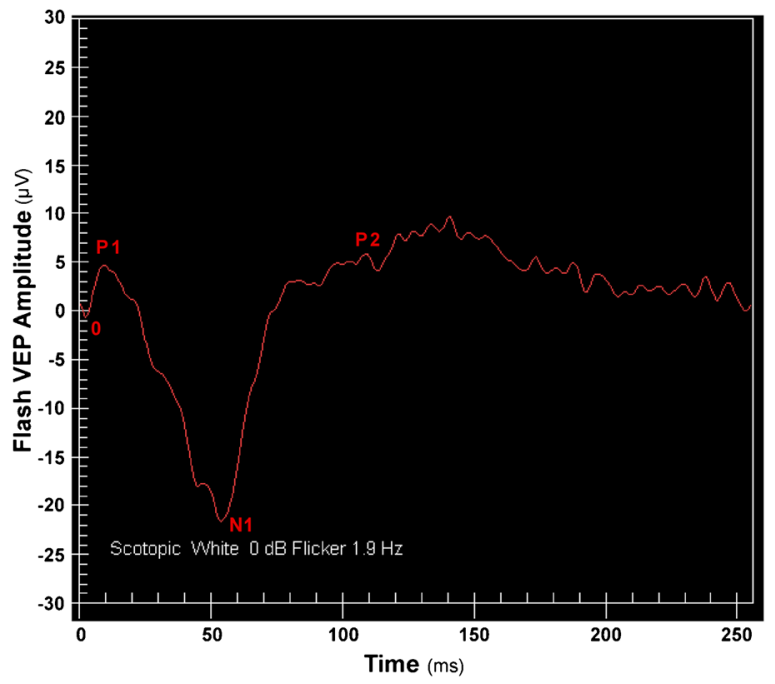

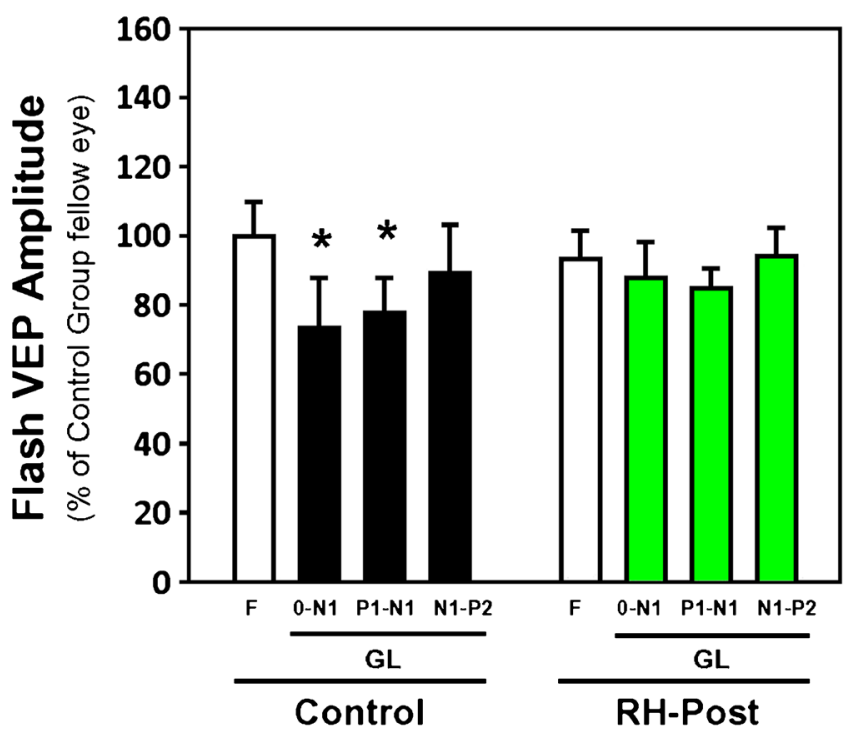

Fig. 6 Flash visual-evoked potential (fVEP) amplitudes and latencies in untreated control mice, and mice with repetitive hypoxic postconditioning (RH-Post). (A) Representative fVEP waveform showing the characteristic locations of the $\mathrm{P} 1, \mathrm{~N} 1$, and $\mathrm{P} 2$ peaks from which the $0-\mathrm{N} 1, \mathrm{P} 1-\mathrm{N} 1$, and N1-P2 amplitudes and latencies were quantified. Left histogram: 0-N1, P1-N1, and N1-P2 amplitudes of the flash VEP waveforms in untreated control mice $(n=9$; black bars $)$ and mice with RH-Post ( $n=11$; green bars) measured after 3 weeks of

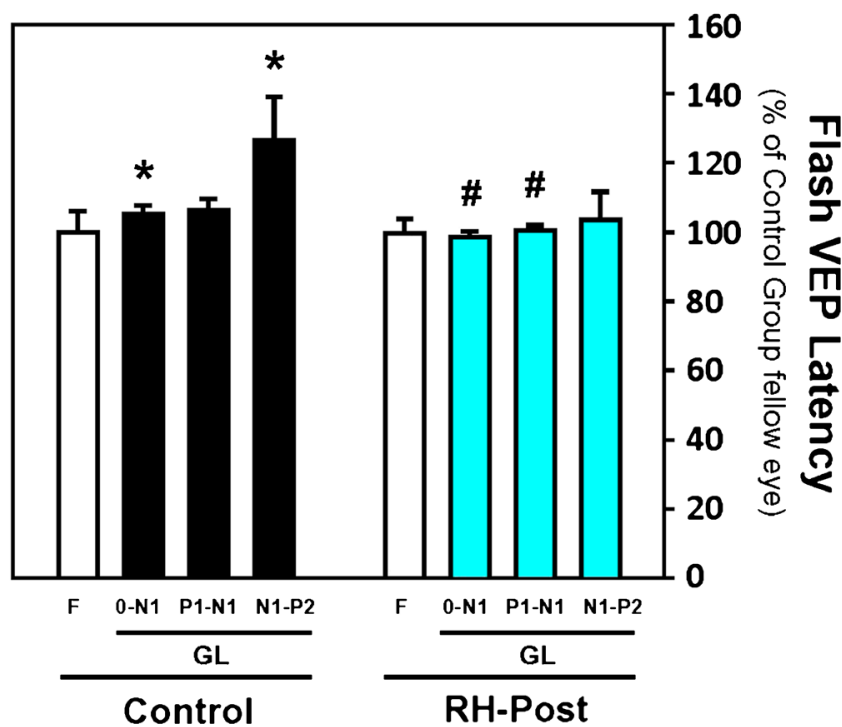

experimental glaucoma (GL) and normalized to amplitudes measured in fellow $(\mathrm{F})$ eyes of the control group. Right histogram: 0-N1, P1-N1, and N1-P2 latencies of the fVEP waveforms in untreated control mice (black bars) and mice with RH-Post (blue bars) measured after 3 weeks of GL and also normalized to latencies measured in $\mathrm{F}$ eyes of the control group. Mean \pm SEM. ${ }^{*} p<0.05 v s$ amplitude or latency in respective fellow eye; ${ }^{\#} p<0.05$ vs respective amplitude or latency in experimental eye of matched control group

\section{fVEP} of these apoptosis-undergoing RGCs may have already been destroyed or at least rendered nonimmunoreactive for DAPI during the apoptotic process. Finally, performing TUNEL staining on our 3-week retina samples showed occasional TUNEL-positive cells in the RGC layer of the peripheral retina in mice with 3 weeks of experimental glaucoma, but not elsewhere in the retina (photomicrographs not shown). Taken together, these results indicate that our episcleral vein ligation method for inducing sustained elevations in IOP do not cause retinal ischemia.
A representative fVEP trace is provided, with reference waveform peaks identified (Fig. 6). At baseline, the three fVEP waveform amplitudes did not differ significantly $(p=0.597$, $p=0.860$, and $p=0.944$, respectively) between control $(n=9)$ and experimental $(n=11)$ groups. Figure 6 shows that, in untreated control mice, the $0-\mathrm{N} 1$ and $\mathrm{P} 1-\mathrm{N} 1$ amplitudes of the fVEP waveform were reduced $27 \pm 14 \%(p=0.016)$ and $22 \pm 10 \%(p=0.008)$, respectively, relative to fellow eyes after 3 weeks of experimental glaucoma; the N1-P2 amplitude 


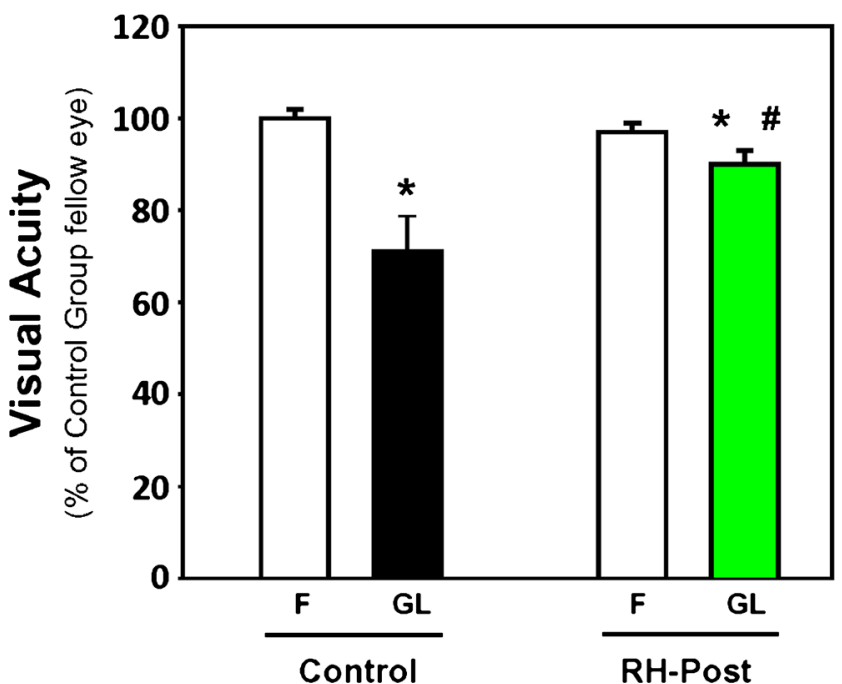

Fig. 7 Visual acuity (VA) in untreated control mice and mice with repetitive hypoxic postconditioning (RH-Post). VA in control mice ( $n=$ 10 ; black bar) and mice with RH-Post ( $n=11$; green bar), measured by optometry after 3 weeks of experimental glaucoma (GL) and normalized to VA in fellow (F) eyes of the control group. Mean \pm SEM. ${ }^{*} p<0.05 v s$ respective fellow eye; ${ }^{\#} p<0.05$ vs matched control group

remained statistically unchanged (reduced $11 \pm 14 \%$ ). However, in RH-Post mice, the extent of disease-induced fVEP amplitude reduction was attenuated, with $0-\mathrm{N} 1$ and $\mathrm{P} 1-\mathrm{N} 1$ amplitudes reduced only $9 \pm 5 \%$ and $6 \pm 4 \%$, respectively; both waveform amplitudes were not significantly different ( $p=0.175$ and 0.102 , respectively) from those measured in the fellow eye. This represented a degree of protection of

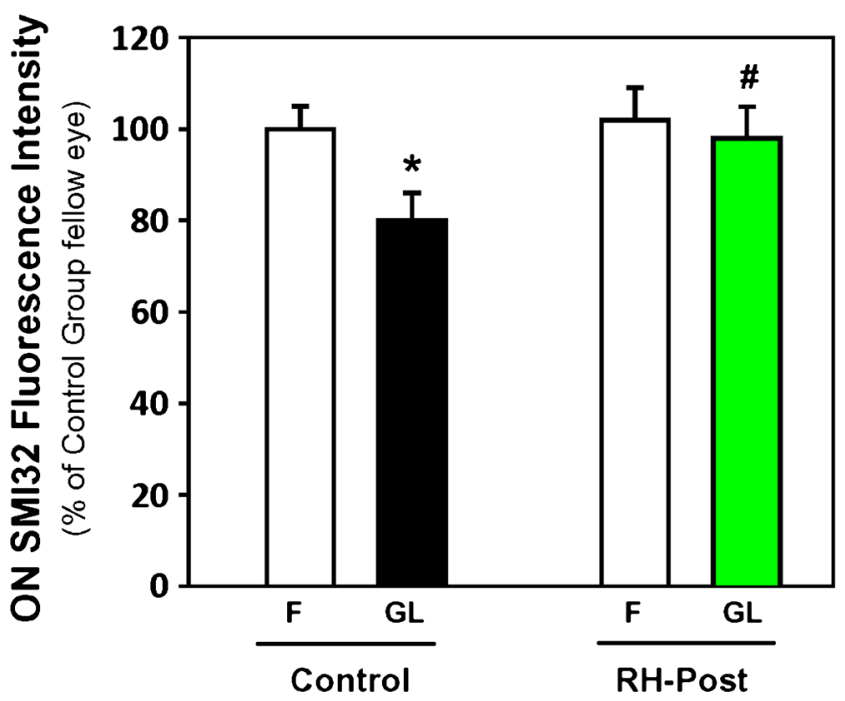

Fig. 8 SMI32 fluorescence intensity in postlaminar optic nerve $(\mathrm{ON})$ of untreated control mice, and mice with repetitive hypoxic postconditioning (RH-Post). Fluorescence intensity, normalized to levels in the fellow (F) ON of the control group in control mice $(n=12$; black bar) and mice with RH-Post ( $n=9$; green bar) measured after 3 weeks of experimental glaucoma (GL). Mean \pm SEM. ${ }^{*} p<0.05 v s$ respective fellow eye; ${ }_{p}^{*}<0.05$ vs matched control group

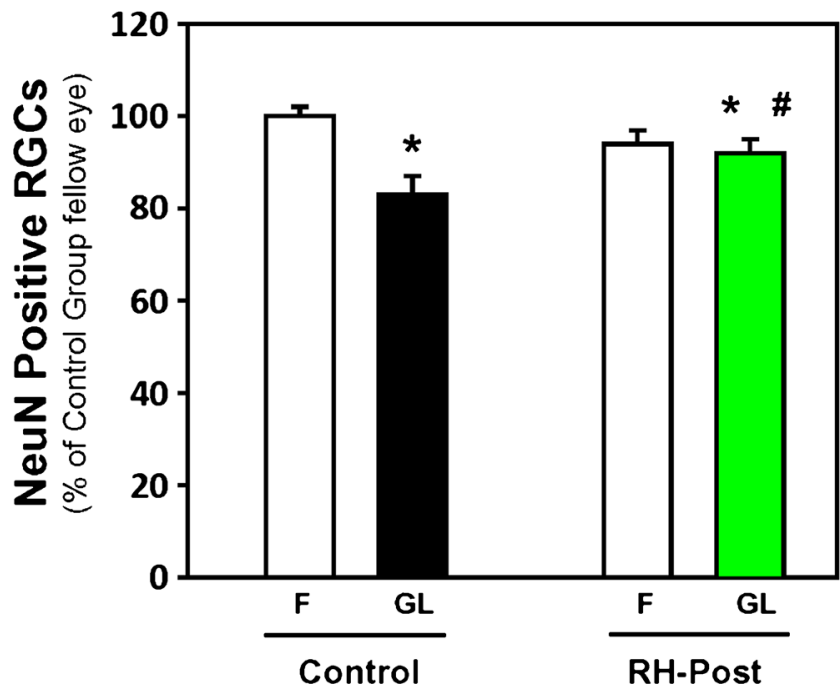

Fig. 9 Total NeuN-positive retinal ganglion cell (RGC) soma in peripheral retinae from untreated control mice and mice with repetitive hypoxic postconditioning (RH-Post). NeuN-positive RGC soma in 12 regions of peripheral retina were quantified and normalized to numbers measured in the fellow $(\mathrm{F})$ retina of the control group in control mice $(n=$ 13; black bar) and mice with RH-Post ( $n=11$; green bar) after 3 weeks of experimental glaucoma (GL). Mean \pm SEM. ${ }^{*} p<0.05 v s$ respective fellow eye; ${ }^{*} p<0.05$ vs matched control group

$66 \%(p=0.068)$ and $71 \%(p=0.058)$, respectively, for these metrics of visual performance.

fVEP waveform latencies did not differ significantly $(p=$ $0.469, p=0.849$, and $p=0.732$, respectively) between control $(n=9)$ and experimental $(n=11)$ groups. Also shown in Fig. 6, in the untreated controls subjected to 3 weeks of intraocular hypertension, the duration of the $0-\mathrm{N} 1$ and N1-P2 waveforms were significantly prolonged by $5 \pm 3 \%(p=0.039)$ and $26 \pm$ $12 \%(p=0.004)$; the duration of the $\mathrm{P} 1-\mathrm{N} 1$ waveform was lengthened $6 \pm 3 \%$, but this did not reach statistical significance $(p=0.148)$. In RH-Post mice, however, the latencies defining the fVEP response after 3 weeks of disease were no different $(p=0.120-0.700)$ than those measured in fellow eyes, and two of the three latency periods $(0$ $\mathrm{N} 1$ and $\mathrm{P} 1-\mathrm{N} 1)$ were significantly shorter $(p=0.020$ and $p=0.007$, respectively) than those same metrics in the control mice not receiving RH-Post.

VA

Baseline VA did not differ significantly between eyes in animals from the untreated control group $(p=0.651 ; n=10)$ nor between eyes in animals from the RH-Post-treated group $(p=0.969 ; n=11)$. Baseline VA in the fellow eyes of the control group was not significantly different $(p=0.309)$ from that in the RH-Post group. Figure 7 shows that, in response to 3 weeks of intraocular hypertension, VA in untreated control mice was reduced $29 \pm 8 \%(p<0.001)$ relative to fellow eyes, whereas in mice receiving RH-Post $(n=11)$, VA was only 
reduced $7 \pm 3 \%$ [but still significantly lower $(p=0.042)$ than that measured in fellow eyes]. Relative to the control mice, this represented a significant, $66 \%$ improvement $(p=0.004)$ in VA as a result of the RH-Post treatment.

\section{RGC Axon Viability}

There was no statistically significant difference $(p=0.749)$ in postlaminar SMI32 fluorescence, a metric of axon integrity, between the fellow eyes of the untreated control group $(n=12)$ and RH-Post group $(n=9)$. As shown in Fig. 8 and consistent with our previous studies [9-11], 3 weeks of experimental glaucoma resulted in a significant loss of SMI32 in the postlaminar optic nerve, as revealed by quantitative SMI32 immunohistochemistry. Specifically, a $20 \pm 6 \%(p<0.001)$ reduction in postlaminar SMI32 fluorescence intensity was measured in the experimental eyes of the untreated controls relative to their fellow eyes. However, in animals treated with RH-Post, postlaminar SMI32 fluorescence was only reduced $4 \pm 3 \%$ [a change not significantly different $(p=0.301)$ from fellow eyes]. Thus, with respect to this structural metric of axon loss, RH-Post protected $80 \%(p=0.043)$ of axons in the postlaminar optic nerve that would have been lost without treatment.

\section{RGC Soma Viability}

There was no statistically significant difference $(p=0.183)$ in the number of NeuN-positive RGC soma between the fellow eyes of the untreated control group ( $n=13)$ and RH-Post group $(n=11)$. Figure 9 shows that, as with axonal dropout, 3 weeks of experimental glaucoma also resulted in significant RGC soma loss, as revealed by quantitative NeuN immunohistochemistry. Consistent with what we reported previously in this model using NeuN or other RGCspecific markers [9-11], overall RGC soma counts across the peripheral retina were reduced $17 \pm 4 \%$ $(p<0.001)$ in the experimental eyes of untreated mice, relative to fellow eyes. RGC soma loss was significant across all quadrants, with reductions of $21 \%(p=0.006$ vs fellow eye), $16 \%(p=0.010), 17 \%(p<0.001)$, and $16 \%(p<0.001)$ in the dorsal-nasal, ventral-nasal, dorsal-temporal, and ventral-temporal quadrants, respectively (data not shown). In the experimental eyes of mice that received RH-Post $(n=11)$, however, overall RGC soma counts were only reduced $2 \pm 1 \%(p=0.014 \mathrm{vs}$ fellow eye), indicating an overall rescue of $88 \%$ $(p<0.001)$ of RGC soma by RH-Post.

By quadrant, RGC soma number in the experimental eyes of RH-Post mice was not significantly different from the corresponding quadrant in the fellow eyes, suggestive of complete protection across all quadrants (data not shown). Specifically, in RH-Post mice, we measured a $12 \%(p=$
$0.978)$ loss in the dorsal-nasal quadrant and a $4 \%(p=$ 0.365 ) loss in the ventral-temporal quadrant; RGC soma numbers in the ventral-nasal and dorsal-temporal quadrants were actually $3 \%(p=0.278)$ and $2 \%(p=0.966)$ higher than those in the corresponding quadrants of the fellow eye. Comparing RGC soma numbers by quadrant between untreated controls and RH-Post mice revealed that the extent of rescue was $42 \%$ $(p=0.297)$ for dorsal-nasal, $119 \%(p=0.011)$ for ventralnasal, $112 \%(p=0.183)$ for dorsal-temporal, and $75 \%$ for dorsal-nasal $(p=0.706)$; note, only the ventral-nasal quadrant exhibited statistically significant protection. Collectively, these findings indicate that RGC soma loss can be consistently detected within animals when analyzed by quadrants, but documenting RGC soma protection between animals as a result of RH-Post treatment is best evidenced by quantifying RGC soma numbers across the entire peripheral retina.

\section{Discussion}

The results of the present study in an inducible mouse model of open-angle glaucoma reveal that repetitive hypoxic postconditioning during the initial 3 weeks of this neurodegenerative disease significantly abrogates functional and morphologic metrics of RGC injury/death. Specifically, glaucoma-induced reductions in overall visual performance (as assessed by fVEPs), VA (determined by optokinetic tracking), RGC soma number in the peripheral retina (by NeuN immunohistochemistry), and RGC axon integrity at the level of the postlaminar optic nerve (by SMI32 immunohistochemistry) - the extent of which were collectively indicative of mild-to-moderate disease in untreated mice-were all robustly blocked in animals treated with RH-Post. These findings indicate that epigenetic responses capable of protecting RGCs can be induced in a sustained fashion after disease onset, and suggest that these pleiotropic, survival-enhancing mechanisms could serve as novel therapeutic targets for patients with glaucoma.

To date, the use of both preconditioning and postconditioning strategies to activate endogenous mechanisms of cytoprotection are widespread in the CNS literature, dating back to the early 1990; however, these studies have been confined almost exclusively to acute injury paradigms. In these settings, the adaptive response induced by the conditioning stimulus is short-lasting, abrogating the extent of an injury process that, while severe, typically 'matures' within hours or a couple of days. Our discovery that repetitive presentations of the conditioning stimulus could extend the duration over which both retina and brain could resist acute ischemic injury $[8,26]$, a finding later validated by others in models of acute ischemic brain injury [27-30], carried the implicit assumption that the long-lasting, prosurvival phenotype induced epigenetically by repetitive conditioning might also 
protect against chronic disease. Indeed, we showed that six short bouts of systemic hypoxia over a 2-week period prior to the onset of experimental glaucoma reduced the resultant loss of RGC soma and axons that occurred over the subsequent 10 weeks of disease [9]. Despite this success, given that the clinical applicability of preconditioning against future disease seems limited, we undertook the present study of postconditioning efficacy.

While postconditioning against acute brain injury, using a variety of postconditioning stimuli and a number of injury endpoints, is well established, postconditioning for ophthalmologic disorders is not. For acute retinal ischemic injury, postconditioning with brief ischemia or carbon monoxide has proven efficacious [31-34], as has environmental enrichment [35]. Studies of postconditioning for more chronic retinal injury paradigms, however, are very limited [36, 37]. That repetitive postconditioning might provide a viable treatment strategy for glaucoma is supported by two preclinical studies to date. One is our previous study showing RGC soma and axon protection in the same inducible mouse model of glaucoma by intermittent hypoxic preconditioning before disease onset [9]. The second reports functional and histological metrics of protection in rats postconditioned weekly with brief local ischemia during the period of intraocular hypertension [38]. Our current observations extend these latter findings in several ways. First, we show that exposing conscious animals to intermittent systemic hypoxia, a noninvasive postconditioning stimulus, can promote glaucoma resistance without the requirement for inducing repetitive anesthesia and/ or repetitive, direct retinal ischemia. Second, we demonstrate postconditioning efficacy in a model of glaucoma exhibiting progressive, time-dependent RGC loss secondary to IOP elevation by a relatively common episcleral vein occlusion approach [9-11, 39-44], in contradistinction to a more obscure model dependent on weekly anterior chamber injections of chondroitin sulfate to elevate IOP [38]. Third, we now document that glaucomatous protection by postconditioning is feasible in mice. Fourth, although both studies histologically quantified significant improvements in soma survival and axon integrity in postconditioned animals, we provided more extensive fVEP amplitude and latency metrics, and we also measured postconditioning-induced enhancements in VA. Independent of model and methodologies, our findings indicate that postconditioning-based treatments, repeated at defined intervals during the progression of disease, offer the potential to significantly abrogate glaucomatous damage.

Generally speaking, quantitative metrics of visual performance reflect the extent of both injury and protection that can only be inferred by morphologic analyses; moreover, functional alterations are often seen in glaucoma in the absence of gross changes in retinal cell structure $[45,46]$, resulting in nonlinear structure-function relationships [47, 48]. In our model, impairments in visual function and performance to levels of about $70-75 \%$ of fellow eye controls, concomitant with optic nerve axon integrity and soma survival on the order of $80-85 \%$ of fellow eye controls, are indicative of mild-tomoderate injury after 3 weeks of sustained IOP elevation. Importantly, RH-Post was efficacious in abrogating all of these RGC injury metrics in the present study, and confirms that improvements in visual performance are feasible with this therapy.

We also advanced findings in the present study corroborating our claim that, in our glaucoma model, RGCs are not dying from ischemia secondary to vein ligation-induced choroidal damage, but from sustained elevations in IOP. This is likely the result of the fact that no penetration of the sclera occurs when we ligate the episcleral veins, thereby avoiding damage to the underlying choroidal tissue secondary to the focal heating caused by cautery or laser treatments [41, 49, 50]. Our extensive histological examinations of the retina revealed no evidence of changes reflecting even the mildest of ischemic injury in the inner or outer nuclear layers, nor any shrinkage of overall retinal thickness, at any postischemic time-changes that would be expected with retinal ischemia. Moreover, at no postischemic time point could we find cleaved caspase-9- or caspase-3-positive cells, or TUNEL-positive cells, in any layer other than the ganglion cell layer in glaucomatous eyes, indicating that no ischemia-induced apoptotic changes in non-RGC cells resulted from vein ligation. Other investigators employing a similar episcleral vein occlusion approach for IOP elevation in mice and rats also did not report morphologic evidence of inner retinal injury nor changes in retinal blood vessels [40-44, 49, 51-57]. Moreover, changes in the extent of reduction of ganglion cell-dependent positive and negative scotopic threshold response (pSTR and nSTR, respectively) amplitudes in mice with laser ablation of episcleral veins directly correlated with the extent of relative IOP elevation [51]. Thus, the findings we report herein, together with the extensive accumulated evidence of others, are consistent with the loss of RGCs secondary to sustained elevations in IOP and not ischemia.

The significant caveat of the present study is that the mechanistic basis for such robust functional/structural protection remains unexplored at this juncture. Given that the progressive RGC injury occurring in glaucoma is characterized by a multifactorial pathology putatively involving a host of excitotoxic, inflammatory, immune, vascular, biomechanical, and other factors [58-60], and that the mechanisms dictating RGC soma and RGC axon loss may be quite distinct [61-63], the epigenetic changes induced by RH-Post will likely be extensive in order to account for the magnitude of the protection achieved. It is also worth noting that, although exposures to intermittent systemic hypoxia may not ultimately be adopted as a clinical treatment for glaucoma patients, this very stimulus has established a strong record for protection against a variety of acute and chronic diseases in the CNS [27-30, 64-67], and other tissues [68-70], and may not be easily mimicked by a pharmacologic, monotherapy approach. 
In conclusion, the functional and structural findings presented herein document that postconditioning during disease can robustly reduce the progressive glaucomatous injury of RGCs and the attendant vision loss. Further studies to elucidate the proximal molecular mediators of this hypoxia-driven response may inform possible therapeutic agents capable of protecting as robustly as intermittent hypoxia did here. But our study makes clear that an epigenetics-based therapeutic strategy can provide a viable treatment approach for patients with glaucoma.

\begin{abstract}
Acknowledgments This study was supported by National Institutes of Health EY18607 (J.M.G., Y.Z.), American Health Assistance Foundation National Glaucoma Foundation (J.M.G., Y.Z.), EY02687 (Department of Ophthalmology, Washington University), National Institutes of Health Neuroscience Blueprint Interdisciplinary Core Grant P30 NS057105 (Washington University), the Hope Center for Neurological Disorders (Washington University), and the Spastic Paralysis Research Foundation of the Illinois-Eastern Iowa District of Kiwanis International. We thank Dr. Sheng-Kwei (Victor) Song at the Department of Radiology at Washington University for use of the optometry instrumentation, and Anne Hennig at the Department of Ophthalmology for assisting with the flash visual-evoked potential recordings.
\end{abstract}

Required Author Forms Disclosure forms provided by the authors are available with the online version of this article.

\section{References}

1. Quigley HA. Glaucoma. Lancet 2011;377:1367-1377.

2. Gidday JM. Cerebral preconditioning and ischaemic tolerance. Nat Rev Neurosci.2006; 7:437-448

3. Dirnagl U, Becker K, Meisel A. Preconditioning and tolerance against cerebral ischaemia: from experimental strategies to clinical use. Lancet Neurol 2009;8:398-412.

4. Meller R, Simon RP. Tolerance to Ischemia - an increasingly complex biology. Transl Stroke Res 2013;4:40-50.

5. Roth S, Li B, Rosenbaum PS, et al. Preconditioning provides complete protection against retinal ischemic injury in rats. Invest Ophthalmol Vis Sci 1998;39:777-785.

6. Zhu Y, Ohlemiller KK, McMahan BK, Gidday JM. Mouse models of retinal ischemic tolerance. Invest Ophthalmol Vis Sci 2002;43:19031911.

7. Roth S, Dreixler JC. Ischemic pre- and post-conditioning in the retina. In: J.M. Gidday et al. (eds) Innate tolerance in the CNS: Translational neuroprotection by pre- and post-conditioning. Springer, New York, 2012, pp. 541-550.

8. Zhu Y, Zhang Y, Ojwang BA, Brantley MA, Jr., Gidday JM. Longterm tolerance to retinal ischemia by repetitive hypoxic preconditioning: Role of HIF-1alpha and heme oxygenase-1. Invest Ophthalmol Vis Sci 2007;48:1735-1743.

9. Zhu Y, Zhang L, Schmidt JF, Gidday JM. Glaucoma-induced degeneration of retinal ganglion cell soma and axons prevented by hypoxic preconditioning: A model of 'glaucoma tolerance'. Mol Med 2012;18:697-706.

10. Zhu Y, Zhang L, Sasaki Y, Milbrandt J, Gidday JM. Protection of mouse retinal ganglion cell axons and soma from glaucomatous and ischemic injury by cytoplasmic overexpression of Nmnat1. Invest Ophthalmol Vis Sci 2013;54:25-36.
11. Zhu Y, Zhang L, Gidday JM. Role of HIF-1 $\alpha$ in preconditioninginduced protection of retinal ganglion cells in glaucoma Mol Vis 2013; 19:2360-2372.

12. Wang WH, Millar JC, Pang IH, Wax MB, Clark AF. Noninvasive measurement of rodent intraocular pressure with a rebound tonometer. Invest Ophthalmol Vis Sci 2005;46:4617-4621.

13. Hegedus B, Hughes FW, Garbow JR, et al. Optic nerve dysfunction in a mouse model of neurofibromatosis-1 optic glioma. J Neuropathol Exp Neurol 2009;68:542-551.

14. You Y, Klistorner A, Graham SL. Visual evoked potential recording in rodents. In: Pilowsky PM (ed.) Stimulation and inhibition of neurons. Neuromethods. Springer, New York, 2013, pp. 275-85.

15. Prusky GT, Alam NM, Beekman S, Douglas RM. Rapid quantification of adult and developing mouse spatial vision using a virtual optomotor system. Invest Ophthalmol Vis Sci 2004;45:4611-4616.

16. Douglas RM, Alam NM, Silver BD, McGill TJ, Tschetter WW, Prusky GT. Independent visual threshold measurements in the two eyes of freely moving rats and mice using a virtual-reality optokinetic system. Vis Neurosci 2005;22:677-684.

17. Dieterich DC, Trivedi N, Engelmann R, Gundelfinger ED, GordonWeeks PR, Kreutz MR. Partial regeneration and long-term survival of rat retinal ganglion cells after optic nerve crush is accompanied by altered expression, phosphorylation and distribution of cytoskeletal proteins. Eur J Neurosci 2002;15:1433-1443.

18. Jakobs TC, Libby RT, Ben Y, John SWM, Masland RH. Retinal ganglion cell degeneration is topological but not cell type specific in DBA/2J mice. J Cell Biol 2005;171:313-325.

19. Raymond ID, Pool AL, Vila A, Brecha NC. A Thy1-CFP DBA/2J mouse line with cyan fluorescent protein expression in retinal ganglion cells. Vis Neurosci 2009;26:453-465.

20. Lin B, Wang SW, Masland RH. Retinal ganglion cell type, size, and spacing can be specified independent of homotypic dendritic contacts. Neuron 2004;43:475-485.

21. Coombs J, van der List D, Wang GY, Chalupa LM. Morphological properties of mouse retinal ganglion cells. Neuroscience 2006;140: 123-136.

22. Beirowski B, Babetto E, Coleman MP, Martin KR. The WldS gene delays axonal but not somatic degeneration in a rat glaucoma model. Eur J Neurosci 2008;28:1166-1179.

23. Buckingham BP, Inman DM, Lambert W, et al. Progressive ganglion cell degeneration precedes neuronal loss in a mouse model of glaucoma. J Neurosci 2008;28:2735-2744.

24. Raymond ID, Vila A, Huynh U-CN, Brecha NC. Cyan fluorescent protein expression in ganglion and amacrine cells in a thy1-CFP transgenic mouse retina. Mol Vis 2008;14:1559-1574.

25. Wolf HK, Buslei R, Schmidt-Kastner R, et al. NeuN: a useful neuronal marker for diagnostic histopathology. J Histochem Cytochem 1996;44:1167-1171.

26. Stowe AM, Altay T, Freie AB, Gidday JM. Repetitive hypoxia extends endogenous neurovascular protection for stroke. Ann Neurol 2011;69:975-985.

27. Tsai YW, Yang YR, Chen GH, Chang HC, Wang RY. The time window of intermittent hypoxia intervention after middle cerebral artery occlusion. Chin J Physiol 2008;51:324-328.

28. Tsai Y-W, Yang Y-R, Wang PS, Wang R-Y. Intermittent hypoxia after transient focal ischemia induces hippocampal neurogenesis and c-Fos expression and reverses spatial memory deficits in rats. PLoS One 2011;6:e24001.

29. Rybnikova E, Vorobyev M, Pivina S, Samoilov M. Postconditioning by mild hypoxic exposures reduces rat brain injury caused by severe hypoxia. Neurosci Lett 2012;513:100-105.

30. Galle AA, Jones NM. The neuroprotective actions of hypoxic preconditioning and postconditioning in a neonatal rat model of hypoxic-ischemic brain injury. Brain Res 2013;1498:1-8 
31. Fernandez DC, Bordone MP, Chianelli MS, Rosenstein RE. Retinal neuroprotection against ischemia-reperfusion damage induced by postconditioning. Invest Ophthalmol Vis Sci 2009;50:3922-3930.

32. Dreixler JC, Shaikh AR, Alexander M, Savoie B, Roth S. Postischemic conditioning in the rat retina is dependent upon ischemia duration and is not additive with ischemic pre-conditioning. Exp Eye Res 2010;91:844-852.

33. Dreixler JC, Poston JN, Shaikh AR, et al. Delayed post-ischemic conditioning significantly improves the outcome after retinal ischemia. Exp Eye Res 2011;92:521-527.

34. Schallner N, Fuchs M, Schwer CI, et al. Postconditioning with inhaled carbon monoxide counteracts apoptosis and neuroinflammation in the ischemic rat retina. PLoS One 2012;7:e46479.

35. Dorfman D, Fernandez DC, Chianelli M, Miranda M, Aranda ML, Rosenstein RE. Post-ischemic environmental enrichment protects the retina from ischemic damage in adult rats. Exp Neurol 2013;240:146156.

36. Fernandez DC, Sande PH, Chianelli MS, Aldana Marcos HJ, Rosenstein RE. Induction of ischemic tolerance protects the retina from diabetic retinopathy. Am J Pathol 2011;178:2264-2274.

37. Liu X, Sha O, Cho EY. Remote ischemic postconditioning promotes the survival of retinal ganglion cells after optic nerve injury. J Mol Neurosci 2013;51:639-646.

38. Belforte N, Sande PH, de Zavalia N, et al. Ischemic tolerance protects the rat retina from glaucomatous damage. PLoS One 2011;6:e23763.

39. Ji J, Chang P, Pennesi ME, et al. Effects of elevated intraocular pressure on mouse retinal ganglion cells. Vis Res 2005;45:169-179.

40. Kim HS, Park CK. Retinal ganglion cell death is delayed by activation of retinal intrinsic cell survival program. Brain Res 2005;1057: 17-28.

41. Ruiz-Ederra J, Verkman AS. Mouse model of sustained elevation in intraocular pressure produced by episcleral vein occlusion. Exp Eye Res 2006;82:879-884.

42. Mittag TW, Danias J, Pohorenec G, et al. Retinal damage after 3 to 4 months of elevated intraocular pressure in a rat glaucoma model. Invest Ophthalmol Vis Sci 2000;41:3451-3459.

43. Yu S, Tanabe T, Yoshimura N. A rat model of glaucoma induced by episcleral vein ligation. Exp Eye Res 2006;83:758-770.

44. Doh SH, Kim JH, Lee KM, Park HY, Park CK. Retinal ganglion cell death induced by endoplasmic reticulum stress in a chronic glaucoma model. Brain Res 2010;1308:158-166.

45. Frankfort BJ, Khan AK, Tse DY, et al. Elevated intraocular pressure causes inner retinal dysfunction before cell loss in a mouse model of experimental glaucoma. Invest Ophthalmol Vis Sci 2013;54:762770.

46. Della Santina L, Inman DM, Lupien CB, Horner PJ, Wong RO. Differential progression of structural and functional alterations in distinct retinal ganglion cell types in a mouse model of glaucoma. $\mathrm{J}$ Neurosci 2013;33:17444-17457.

47. Medeiros FA, Zangwill LM, Bowd C, Mansouri K, Weinreb RN. The structure and function relationship in glaucoma: implications for detection of progression and measurement of rates of change. Invest Ophthalmol Vis Sci 2012;53:6939-6946.

48. Harwerth RS, Wheat JL, Fredette MJ, Anderson DR. Linking structure and function in glaucoma. Prog Retin Eye Res 2010;29:249-271.

49. Shareef SR, Garcia-Valenzuela E, Salierno A, Walsh J, Sharma SC. Chronic ocular hypertension following episcleral venous occlusion in rats. Exp Eye Res 1995;61:379-382.

50. Aihara M, Lindsey JD, Weinreb RN. Experimental mouse ocular hypertension: establishment of the model. Invest Ophthalmol Vis Sci 2003;44:4314-4320.
51. Holcombe DJ, Lengefeld N, Gole GA, Barnett NL. Selective inner retinal dysfunction precedes ganglion cell loss in a mouse glaucoma model. Br J Ophthalmol 2008;92:683-688.

52. Laquis S, Chaudhary P, Sharma SC. The patterns of retinal ganglion cell death in hypertensive eyes. Brain Res 1998;784:100-104.

53. Neufeld AH, Sawada A, Becker B. Inhibition of nitric-oxide synthase 2 by aminoguanidine provides neuroprotection of retinal ganglion cells in a rat model of chronic glaucoma. Proc Natl Acad Sci U S A 1999;96:9944-9948.

54. Sawada A, Neufeld AH. Confirmation of the rat model of chronic, moderately elevated intraocular pressure. Exp Eye Res 1999;69:525531.

55. Ahmed FA, Chaudhary P, Sharma SC. Effects of increased intraocular pressure on rat retinal ganglion cells. Int $\mathrm{J}$ Dev Neurosci 2001;19:209-218.

56. Bayer AU, Danias J, Brodie S, et al. Electroretinographic abnormalities in a rat glaucoma model with chronic elevated intraocular pressure. Exp Eye Res 2001;72:667-677.

57. Kanamori A, Nakamura M, Nakanishi Y, et al. Akt is activated via insulin/IGF-1 receptor in rat retina with episcleral vein cauterization. Brain Res 2004;1022:195-204.

58. Almasieh M, Wilson AM, Morquette B, Cueva Vargas JL, Di Polo A. The molecular basis of retinal ganglion cell death in glaucoma. Prog Retin Eye Res 2012;31:152-181.

59. Calkins DJ. Critical pathogenic events underlying progression of neurodegeneration in glaucoma. Prog Retin Eye Res 2012;31:702719 .

60. Janssen SF, Gorgels TG, Ramdas WD, et al. The vast complexity of primary open angle glaucoma: disease genes, risks, molecular mechanisms and pathobiology. Prog Retin Eye Res 2013;37:31-67.

61. Libby RT, Li Y, Savinova OV, et al. Susceptibility to neurodegeneration in a glaucoma is modified by Bax gene dosage. PLoS Genet 2005; $1: 17-26$.

62. Howell GR, Soto I, Libby RT, John SW. Intrinsic axonal degeneration pathways are critical for glaucomatous damage. Exp Neurol 2013;246:54-61.

63. McKinnon SJ, Schlamp CL, Nickells RW. Mouse models of retinal ganglion cell death and glaucoma. Exp Eye Res 2009;88:816-824.

64. Leconte C, Tixier E, Freret $\mathrm{T}$, et al. Delayed hypoxic postconditioning protects against cerebral ischemia in the mouse. Stroke 2009;40:3349-3355.

65. Manukhina EB, Goryacheva AV, Barskov IV, et al. Prevention of neurodegenerative damage to the brain in rats in experimental Alzheimer's disease by adaptation to hypoxia. Neurosci Behav Physiol 2010;40:737-743.

66. Lovett-Barr MR, Satriotomo I, Muir GD, et al. Repetitive intermittent hypoxia induces respiratory and somatic motor recovery after chronic cervical spinal injury. J Neurosci 2012;32:3591-3600.

67. Hayes HB, Jayaraman A, Herrmann M, Mitchell GS, Rymer WZ, Trumbower RD. Daily intermittent hypoxia enhances walking after chronic spinal cord injury: a randomized trial. Neurology 2014;82: 104-113.

68. Serebrovskaya TV. Intermittent hypoxia research in the former soviet union and the commonwealth of independent States: history and review of the concept and selected applications. High Alt Med Biol 2002;3:205-221.

69. Marquez JL, Rubinstein S, Fattor JA, Shah O, Hoffman AR, Friedlander AL. Cyclic hypobaric hypoxia improves markers of glucose metabolism in middle-aged men. High Alt Med Biol 2013; 14:263-272

70. Basovich SN. Trends in the use of preconditioning to hypoxia for early prevention of future life diseases. Biosci Trends 2013;7:23-32. 